\title{
The use of energy drinks in adolescents: a risky behaviour
}

\begin{abstract}
The use of energy drinks in adolescents: a risk behaviour

Objective: to identify the knowledge, perceptions and risks associated with the use of energy drinks (EDs) in adolescents.

Methods: the following databases were consulted for this narrative review: Pubmed, Cinahl, Cuiden Plus and Scopus. Free and controlled language was used (MeSH). There were limitations in terms of language (English and Spanish), the last five years of publication (2014-2019) and adolescents (10-to-19 years old).

Results: twenty-six (26) articles were selected out of $702 ; 82.6 \%$ of these had a quantitative approach, the majority were descriptive cross-sectional studies $(57.6 \%)$. Findings were classified into "knowledge and perceptions by users", "influence in rest and modo" and "substance abuse" The use of EDs was perceived as a typically male behaviour, not healthy, and for sports activities in general; besides, it was associated with physical activity, violent behaviours, worse performance and academic failure, emotional problems, sleep pattern problems, hyperactivity, reckless driving, substance abuse, and alcohol dependency.

Conclusions: lack of information and aggressive marketing campaigns encourage the abuse of energy drinks, which leads to a higher risk of substance abuse. Preparing preventive programs and updating the current ones, as well as nutritional advice and education for health, could be essential in order to solve this problem.
\end{abstract}

Keywords: energy drinks, health-related behaviour, mood disorders, academic performance, athletic performance, use of alcoholic drinks, public health, adolescent behaviour, review
Volume 3 Issue 5 - 2019

\author{
Enrique Bermejo Osaba, María Luisa Cid \\ Galán, Carmen Martin Salinas \\ Department of Nursing, Medicine Faculty, University \\ Autonomous of Madrid, Spain
}

Correspondence: Enrique Bermejo Osaba, Department of Nursing, Medicine Faculty, University Autonomous of Madrid, Arzobispo Morcillo, 4, 28029 Madrid, Spain, Email enriquebermejoosaba@gmail.com

Received: October 05, 2019 | Published: October 16, 2019
Abbreviations: WHO, world health organization; EDs, energy drinks; EFSA, European Food Safety Authority; CNS, central nervous system

\section{Introduction}

The World Health Organization (WHO) warns us that the increased consumption of energy drinks (EDs) could mean a danger to the public health of young people. ${ }^{1}$ These drinks without alcohol, gasified, of great variability in beverage containers and with a degree of carbonation lower than that of a soft drink, are characterized by having a high caffeine content $(320 \mathrm{mg} / \mathrm{L}) .^{2-4}$ The rest of the ingredients are very heterogeneous, from taurine to ginseng, guarana, $\mathrm{B}$ vitamins and carbohydrates. ${ }^{1,2}$ They do not include caloric intake in joules that justify the term "energy", nor any nutritional value, they only contain pharmacologically active substances. They are marketed as drinks that increase athletic performance, being awake, attention, reactivity, concentration and reduce both physical and mental stress. ${ }^{1,2}$ Regarding the regulation of energy drinks, nutritional labelling is governed by the provisions of the "Regulation No1169/2011" for all Member States of the European Union (EE MM) which, establishes that any product with a proportion of more than $150 \mathrm{mg} / \mathrm{L}$ of caffeine should add the proportion in $\%$ or $\mathrm{mg} / 100 \mathrm{~mL}$ and the warning: "High caffeine content. Not recommended for children or pregnant ".

The origin of the EDs dates back to Asia, specifically to Thailand, from where exportation around the world began in the 80 s of the last century. But the popularity was reached with the appearance of the drink "Red bull TM" in 1987 of Austrian origin. ${ }^{6}$ Since 2006, a total of around 500 different ED brands have been commercialized and sales continue increasing. ${ }^{2,6}$ In 2015 they reached around 50 billion dollars and they are expected to reach 60 billion dollars by $2021 .^{3}$ According to data from the European Food Safety Authority (EFSA), it was estimated that the prevalence of consumption among the adolescent population was $68 \%$ among the EE MM in 2013; being more frequent in men than in women. ${ }^{7} 53 \%$ consumed them mixed with alcohol. In Spain with a prevalence of $62 \%, 43 \%$ claimed to consume them mixed with alcohol. ${ }^{7}$ Health experts express that EDs could mean a potential danger to the health of minors, since they produce cardiovascular and cognitive disorders ${ }^{3,8}$ associated with caffeine abuse. The EFSA estimated that the safety limit on caffeine intake in adolescents could be around $3 \mathrm{mg} / \mathrm{kg} /$ day. ${ }^{9}$

This substance, adenosine antagonist at the level of the central nervous system (CNS), in moderate doses produces an improvement in memory, attention, alertness and reactivity in fatigued adults. Currently, it is inadvisable the case of minors because it entails a cognitive overstrain for the brain, and the physiological remedy to relieve fatigue is to take a rest. ${ }^{3}$ However, it is still popular in this age group of the population and the "marketing" campaigns are aimed at adolescents, although tolerance to stimulants at these ages is still to be determined. ${ }^{3}$ In adults, many adverse effects associated with the consumption of EDs have been detected, mainly, tachycardia, hypertension, motor hyperactivity, increased capacity of attention, increased gastric secretion, diuretic effect and temperature rise. Other more rare and severe are rhabdomyolysis, coronary vasospasm, 
supraventricular and / or ventricular arrhythmias, and psychosis. ${ }^{2,8}$ However, more interesting is from the psychosocial prism. The use of EDs is associated with risky behaviors, mainly the use of marijuana and alcohol. ${ }^{2}$ Mixing alcohol with EDs (AmED) has become a risky practice that has increased over the years, with adolescents being regular consumers and the main risk group. ${ }^{3}$ The role of nursing is crucial in order to develop a population-level awareness among adolescents about the risks of EDs, as well as necessary to generate safe environments and, above all, as a promoter to lead adolescents to a responsible consumption of alcohol reached when they come of age. Consequently, the objective of this review is to identify the knowledge, perceptions and risks associated with the consumption of EDs in adolescents in order to justify future nursing interventions for their prevention.

\section{Methods}

Narrative review based on bibliographic searches in four databases. In Cuiden plus and Scopus, free language was used, and in Pubmed

Table I Search strategies and results and Cinahl, both free and controlled language was used based on the descriptors of the "MeSH" thesaurus. The construction of the search statement was carried out according to a division of the terms into 3 large blocks: subject of study, population under study and outcomes in Table 1; which were later unified in the same statement by means of Boolean operators of type AND. Likewise, limitations such as the "English" and "Spanish" language were applied, the last 5 years of publication comparing those articles published from April 2014 to April 2019 and exclusively in Scopus, due to the importance as a filter "Nursing discipline was applied" and thus select those jobs related to the role of nurses and health sciences in general. Likewise it was also considered as inclusion criteria, the work carried out in healthy adolescents (10 to 19 years old), both qualitative and quantitative, fundamentally, cross-sectional studies that will associate the consumption of energy drinks with lifestyles and secondary sources that collate this type of studies were considered as inclusion criteria. As exclusion criteria, work done on young adults, university students, exclusively isotonic or carbonated drinks and expert opinion articles were discarded.

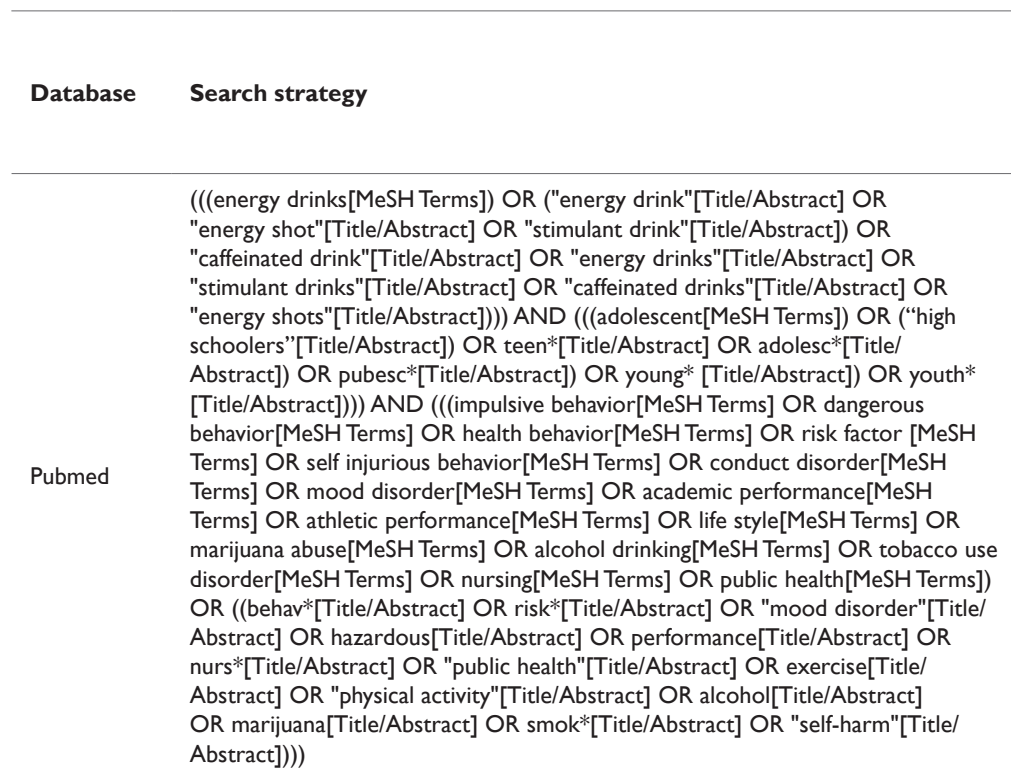

\section{Database Search Strategy}

(((MH "Energy Drinks") OR (TI energy drink OR AB energy drink OR TI energy drinks $O R A B$ energy drinks $O R T I$ caffeinated drink $O R A B$ caffeinated drink ORTI caffeinated drinks $O R A B$ caffeinated drinks OR TI stimulant drink OR AB stimulant drink OR TI stimulant drinks OR AB stimulant drinks OR TI energy shot OR AB energy shot OR TI energy shots OR AB energy shots $)))$ AND (((MH adolescence) OR (TI teen* OR TI "high schoolers" OR TI adolesc* OR TI young* OR TI youth* OR AB teen* OR AB "high schoolers" OR AB adolesc* OR AB young* OR AB youth*))) AND (((MH impulsive behavior OR MH dangerous behavior OR MH health behavior OR MH self-injurious behavior OR MH conduct disorder OR MH mood disorders OR MH academic performance OR MH athletic performance OR MH life style OR MH marijuana abuse OR MH alcohol drinking OR MH tobacco use disorder OR MH nursing OR MH public health OR MH risk factors) OR (TI behav* OR AB behav* OR TI performance OR AB performance OR TI risk* OR $A B$ risk* OR TI "physical activity" OR AB physical activity" OR TI exercise OR AB exercise OR TI "mood disorder" OR AB "mood disorder" OR TI hazardous OR $A B$ hazardous OR TI self-harm OR AB self-harm OR TI smok* OR AB smok* OR TI alcohol OR AB alcohol OR TI marijuana OR AB marijuana OR TI nurs* OR AB nurs* OR TI public health OR AB public health)))

$\begin{array}{llll}377 & 198 & 112 & 18\end{array}$

\begin{tabular}{|c|c|c|c|}
\hline $\begin{array}{l}\text { Studies } \\
\text { retrieved } \\
\text { from } \\
\text { search }\end{array}$ & $\begin{array}{l}\text { Studies } \\
\text { include after } \\
\text { reading of } \\
\text { title }\end{array}$ & $\begin{array}{l}\text { Studies } \\
\text { include after } \\
\text { reading of } \\
\text { abstract }\end{array}$ & $\begin{array}{l}\text { Studies } \\
\text { include after } \\
\text { reading the } \\
\text { complete } \\
\text { study }\end{array}$ \\
\hline
\end{tabular}

\section{Studies include after reading the} study 
Table Coninues..

\begin{tabular}{|c|c|c|c|c|c|}
\hline Database & Search Strategy & $\begin{array}{l}\text { Studies } \\
\text { retrieved } \\
\text { from } \\
\text { search }\end{array}$ & $\begin{array}{l}\text { Studies } \\
\text { include after } \\
\text { reading of } \\
\text { title }\end{array}$ & $\begin{array}{l}\text { Studies } \\
\text { include after } \\
\text { reading of } \\
\text { abstract }\end{array}$ & $\begin{array}{l}\text { Studies } \\
\text { include after } \\
\text { reading the } \\
\text { complete } \\
\text { study }\end{array}$ \\
\hline Cuiden Plus & 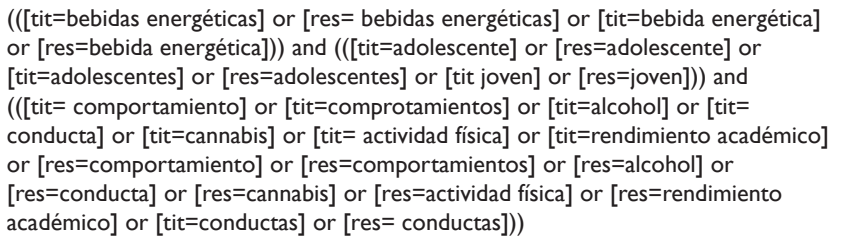 & 2 & 0 & 0 & 0 \\
\hline Scopus & $\begin{array}{l}\text { ((TITLE-ABS-KEY ("energy drinks") OR TITLE-ABS-KEY ("energy drink") OR } \\
\text { TITLE-ABS-KEY ("energy shot") OR TITLE-ABS-KEY ("energy shots") OR TITLE- } \\
\text { ABS-KEY ("stimulant drink") OR TITLE-ABS-KEY ("stimulant drinks") OR TITLE- } \\
\text { ABS-KEY ("caffeinated drink") OR TITLE-ABS-KEY ("caffeinated drinks")) AND } \\
\text { ((TITLE-ABS-KEY (adolesc*) OR TITLE-ABS-KEY (teen*) OR TITLE-ABS-KEY ("high } \\
\text { schoolers") OR TITLE-ABS-KEY (young*) OR TITLE-ABS-KEY (youth*)) AND ( } \\
\text { (TITLE-ABS-KEY (behav*) OR TITLE-ABS-KEY (risk*) OR TITLE-ABS-KEY ("modo } \\
\text { disorder") OR TITLE-ABS-KEY (nurs*) OR TITLE-ABS-KEY ("public health" ) OR } \\
\text { TITLE-ABS-KEY ( exercise ) OR TITLE-ABS-KEY ("physical activity") OR TITLE- } \\
\text { ABS-KEY (alcohol ) OR TITLE-ABS-KEY (marijuan) OR TITLE-ABS-KEY (smok*) } \\
\text { OR TITLE-ABS-KEY ("self harm")) }\end{array}$ & 103 & 13 & 6 & 1 \\
\hline Database & Search Strategy & $\begin{array}{l}\text { Studies } \\
\text { retrieved } \\
\text { from } \\
\text { search }\end{array}$ & $\begin{array}{l}\text { Studies } \\
\text { include after } \\
\text { reading of } \\
\text { title }\end{array}$ & $\begin{array}{l}\text { Studies } \\
\text { include after } \\
\text { reading of } \\
\text { abstract }\end{array}$ & $\begin{array}{l}\text { Studies } \\
\text { include after } \\
\text { reading the } \\
\text { complete } \\
\text { study }\end{array}$ \\
\hline Total & & $\begin{array}{l}\mathrm{N}=702(208 \\
\text { studies } \\
\text { duplicates) }\end{array}$ & $N=26 I$ & $N=|5|$ & $N=26$ \\
\hline
\end{tabular}

\section{Results}

In the searching process, a total of 702 articles were obtained, as shown in Table 2.28 articles were selected, from 25 primary sources (89\%), of which 2 with a qualitative approach $(7.15 \%), 23$ with a quantitative approach (82.15) mostly cross-sectional studies (57.15\%), and 3 articles from secondary sources $(10.7 \%)$. The dossier of the work has been divided into three thematic categories: knowledge and perceptions of consumers, influence on rest and mood and substance abuse.

Table 2 Studies selection

\begin{tabular}{|c|c|c|c|c|}
\hline Study & Year/Country & Objective & Design & Findings \\
\hline $\begin{array}{l}\text { Francis J et } \\
\text { al. }{ }^{10}\end{array}$ & Australia 2017 & $\begin{array}{l}\text { To determine adolescent's knowledge, } \\
\text { motivations and strategies to decrease } \\
\text { consumption of ED. }\end{array}$ & $\begin{array}{l}\text { Focus Group N:4I } \\
\text { (12-15 years) }\end{array}$ & $\begin{array}{l}\text { Enhanced energy, prize, accessibility, peer pressure, pleasant taste and } \\
\text { commercial strategies are facilitators of consumption of ED. }\end{array}$ \\
\hline Scuri S et al." & Italy2019 & $\begin{array}{l}\text { To determine the frequency of } \\
\text { consumption of ED in high school } \\
\text { students. }\end{array}$ & $\begin{array}{l}\text { Cross-Sectional } \\
\mathrm{N}: 1581\end{array}$ & $\begin{array}{l}\text { A } 93 \% \text { of participants know the mainly ingredients of ED. The main } \\
\text { use it to play sport, study and leisure activities. }\end{array}$ \\
\hline $\begin{array}{l}\text { Mansour B } \\
\text { et al. }{ }^{12}\end{array}$ & Israel2019 & $\begin{array}{l}\text { To value the awareness of risk } \\
\text { associated in consumption of ED. }\end{array}$ & $\begin{array}{l}\text { Cross-Sectional } \\
\text { N:400 (16-18 } \\
\text { years) }\end{array}$ & $\begin{array}{l}\text { The consumption is more prevalent in boys. There is inverse } \\
\text { association between knowledge and consumption of EDs. }\end{array}$ \\
\hline $\begin{array}{l}\text { Costa BM et } \\
\text { al. }^{13}\end{array}$ & Australia 2014 & $\begin{array}{l}\text { To explore perceptions, patterns and } \\
\text { contexts of consumption of ED. }\end{array}$ & $\begin{array}{l}\text { Focus Group N: } 40 \\
\text { (12-15 years) }\end{array}$ & $\begin{array}{l}\text { Adolescents have limited knowledge about common ingredients of } \\
\text { EDs, and some have difficulties to distinguish EDs from other drinks. }\end{array}$ \\
\hline Study & Year/Country & Objective & Design & Findings \\
\hline $\begin{array}{l}\text { Costa BM et } \\
\text { al. }^{14}\end{array}$ & Australia 2016 & $\begin{array}{l}\text { To value patterns of consumption of } \\
\text { EDs in adolescents. }\end{array}$ & $\begin{array}{l}\text { Cross-Sectional N: } \\
399 \text { (12-18 years) }\end{array}$ & $\begin{array}{l}\text { Consumption of EDs is prevalent in adolescents, is associated } \\
\text { with psychological symptoms and the maximum number of ED } \\
\text { appropriated in a day varied. }\end{array}$ \\
\hline $\begin{array}{l}\text { Emond JA et } \\
\text { al. }^{15}\end{array}$ & USA 2014 & $\begin{array}{l}\text { To describe the TV programming and } \\
\text { their audience during the advertising } \\
\text { of ED. }\end{array}$ & $\begin{array}{l}\text { Cross-Sectional } \\
\mathrm{N}: 139\end{array}$ & $\begin{array}{l}\text { EDs are advertised in adolescent channels of US network and cable } \\
\text { television. }\end{array}$ \\
\hline $\begin{array}{l}\text { Nowak D et } \\
\text { al. }{ }^{16}\end{array}$ & Poland 2016 & $\begin{array}{l}\text { To examine the consumption of ED in } \\
\text { adolescent athlete. }\end{array}$ & $\begin{array}{l}\text { Cross-Sectional N: } \\
707 \text { (13-16 years) }\end{array}$ & $\begin{array}{l}\text { The } 69 \% \text { of adolescents who consuming EDs are athletes and } \\
\text { reported headache, pain abdominal, nausea, vomiting, insomnia and } \\
\text { anxiety mainly. }\end{array}$ \\
\hline $\begin{array}{l}\text { Gallo Salazar } \\
\text { C et al. }{ }^{17}\end{array}$ & Spain2015 & $\begin{array}{l}\text { To evaluate the effectiveness of } \\
\text { EDs during pre-exercise in physical } \\
\text { performance of elite junior tennis } \\
\text { Player }\end{array}$ & $\begin{array}{l}\text { Experimental } \mathrm{N}: 14 \\
\text { (15-17 years) }\end{array}$ & $\begin{array}{l}\text { The use of ED improves handgrip force, the running intensity and } \\
\text { number of sprints. }\end{array}$ \\
\hline
\end{tabular}


Table Coninues...
Study

Arazi $\mathrm{H}$ et

al. ${ }^{18}$

Abian-Vicen J

et al. ${ }^{19}$

Husarova D

et al. ${ }^{20}$

Marmorstein

$\mathrm{NR}^{21}$

Study

Logan RW et

al. ${ }^{22}$

Holubcikova J

et al. ${ }^{23}$

Schwartz DL

et al. ${ }^{24}$

USA 2014

Iran2016

Spain2014

USA 2017

USA 2017
Year/Country

Slovakia 2017

Year/Country

Slovakia 2017

Korea2017

Cofini $V$ et

al. $^{26}$

Italy 2016

Study

Park S et al. ${ }^{27} \quad \begin{aligned} & \text { South } \\ & \text { Korea2016 }\end{aligned}$

Barrense-Dias Switzerland

$Y$ et al. ${ }^{28}$

2016

Marmorstein

$\mathrm{NR}^{29}$

USA 2019

Choi HJ et

al. ${ }^{30}$

USA 2015

Marczinski

$\mathrm{CA}^{31}$

USA 2014

Study al. ${ }^{32}$

Williams RD

et al..$^{33}$

Holubcikova

et al. $^{34}$

Slovakia 2016

Lalanne $\mathrm{L}$ et al. $^{35}$
Kim SY et al. ${ }^{25}$ South

Bonar EE et

\section{Objective}

To evaluate effectiveness of EDs during pre-exercise in physical performance in female swimmers.

To evaluate effectiveness of ED in precision in throw, jump performance and endurance in basketball players.

To associate the use of digital devices with consumption of Eds and sleeping quality.

To associate the consumption of ED

\section{Objective}

To review the role of brain regard systems in the disruption of circadian

To associate the chronic consumption of EDs with behavioral problems and health of adolescents.

To associate consumption of EDs with hyperactive behavior.

To associate the role of emotiona factors with consumption of EDs

To associate social, psychological and behavioral characteristics with the consumption of EDs.

\section{Objective}

To associate the consumption of ED with mental health problems in isolation or in combination of "junk food".

To examine whether the consumption of ED at 14 years teenagers predicted the substance use at 16 years teenagers.

To associate the consumption of EDs with alcohol use 16 months later.

To associate the consumption of EDs with alcohol consumption in a year.

Review studies which evidence the mixing EDs with alcohol can increase the desire of consumption more alcohol.

\section{Year/Country Objective}

To value the reasons and consequences of mixing alcohol with EDs in emergency department care.

To compare the different between the driving of adolescents who consuming AmED, alcohol and EDs

To associate the consumption of AmED with behavioral problems. with sleep problems. rhythms in adolescents

Design

Experimental N: 36 (I2-14 years)

Experimental N: 16 (13-16 years)

Cross-Sectional N: 7595 ( I I- 16 years)

Cross-Sectional N 127 (12-15 years)

Design

Bibliographica review

Cross-Sectional N: 8977 (II-I5 years)

Cross-Sectional

$N: 1649$

Cross-Sectional $\mathrm{N}: 121106$ (13-18 years)

Cross-Sectional $\mathrm{N}: 450$ ( $10-18$ years)

Design

Cross-Sectional $\mathrm{N}: 68043$ (12-18 years)

Longitudinal N:62I (14-16 years)

Longitudinal N: 134 (10-14 years)

Longitudinal N:780

The consumption of EDs is a risk factor of alcohol consumption.

Bibliographica review

Design

Cross-Sectional N: 439 (14-20 years)

Cross-Sectional N: 1305

Cross-Sectional N: 8502 ( $11-15$ years)

To review the cognitive impact and perception in the intoxication of AmED.

\section{Findings}

The use of ED reduces the record to complete $100 \mathrm{~m}$ swim Crawl.

The ED increases the height of counter movement jump test and I5 seconds maximal jumping test.

More time spend in digital devices is associated with higher consumption of ED and a lower quality of sleeping.

The consumption of ED is associated with daytime fatigue and initial insomnia.

Findings

Evidence suggest ED can contribute in disruption of circadian rhythms.

The consumption is more prevalent in boys and report more health problems, behavioral problems and negative scholar experiences.

Higher risk of inattention and hyperactivity in adolescent who consuming EDs.

Lack of sleeping, stress, suicidal attempts and low school performance are associated with consumption of ED.

The consumption is more prevalent in boys. There's no significative association with anxiety and depressive mood.

Findings

The consumption of ED is significative associated with sleep dissatisfaction, stress, depressive mood, suicidal ideation, suicide plan and suicide attempt.

The consumption of ED at I 4 years predicted the consumption of substance use at 16 .

Early consumption of ED in adolescents predicted later alcohol consumption.

New studies help to explain why AmED increase the desire of consumption more alcohol.

\section{Findings}

AmED is associated with high risk driving, sex practice after consumption of alcohol and drug use

AmED is associated with high risk driving.

Adolescents who consuming AmED tent to adopt aggressive behavior.

Systematic Review 


\section{Knowledge and perceptions of consumers}

Adolescents identify an "energy drink" with large amounts of sugar, caffeine and energy. ${ }^{10}$ There are adolescents who don't know the main ingredients and often confuse EDs with isotonic drinks and cola drinks. Many of them are not able to identify any adverse effects and mistakenly consider that there are equivalences between beverage containers. ${ }^{10,11}$ It is possible that the knowledge deficit may act as a facilitating factor for excessive consumption of EDs. According to the Israeli cross-sectional study by Mansour et al., ${ }^{12}$ which compares the degree of knowledge among adolescents who do not consume EDs and those who do so regularly, adolescents who do not consume EDs have more information about the adverse effects and ingredients. Likewise, it is common for adolescents to perceive the consumption of EDs as a habit of the masculine gender, unhealthy and of sports practices in general. ${ }^{10,13,14}$ In the USA cross -sectional study by Emond JA et al., ${ }^{15}$ it is observed how the "marketing" associated with the EDs focuses on the promotion of sports practices. Adolescents' athletes, who consume EDs, do it daily, usually 1 container of $250 \mathrm{~mL}$ per sports session and they commonly describe a feeling of vigour after consumption (16-18). Investigations conducted in this regard, such as those by Gallo-Salazar C et al., ${ }^{17}$ Arazi $\mathrm{H}$ et al., ${ }^{18}$ and Abian-Vicen J et al., ${ }^{19}$ have demonstrated the presence of an ergogenic effect compared to placebo when consuming a ED during pre-exercise (30 minutes or 1 hour before exercise) in sports such as tennis, swimming and basketball. The results were correlated with previous studies in team sports such as rugby, football, basketball and volleyball. However, there were a part of the participants who reported adverse effects after consumption, mainly insomnia, nausea or gastrointestinal discomfort, despite the controlled conditions and two of the studies did not exceed $3 \mathrm{mg} / \mathrm{kg} /$ day. ${ }^{17,19}$

\section{Influence on rest and mood}

It is known that EDs can act as an environmental factor that modulates circadian rhythms, generating a phenomenon known as "sleep deprivation." Chronic use of EDs have been directly associated with difficulty in falling asleep, less sleep, insomnia and daytime fatigue. These consequences constitute a risk factor for presenting depression, anxiety, substance use, school absenteeism, poor academic performance and adoption of aggressive behaviours such as bullying or fighting within the school environment. ${ }^{20,21}$ Daily life requires adolescents to wake up early, so bad sleep hygiene habits lead to less hours of sleep that ultimately lead to difficulty falling asleep. This situation caused by EDs, favours the perpetuation of the consumption habit to be able to counteract daytime fatigue, which leads them to a worse academic performance and to live the night world prematurely, where they are more exposed to substance abuse. ${ }^{22}$ In fact, evening chronotypes are associated with depression, decreased reward circuits, poor self-perception, impulsivity and experience new sensations. We believe that sustained sleep deprivation could lead to a damage on adolescents' brain circuits, with a decrease in reward circuits. This seems to be linked to a tendency to suffer from depression and selfharm episodes and to a continuous search to experience new things. ${ }^{22}$ This is related to the results of the studies by Holubcikova $J$ et al., ${ }^{23}$ Schwartz DL et al.. ${ }^{24}$ and Kim SY et al., ${ }^{25}$ in those with higher consumption of EDs, the association between anxious, depressive, hyperactive, violent and self-injurious behaviours increase. However, in the cross-sectional study by Cofini $\mathrm{V}$ et al., ${ }^{26}$ this association was not significant, but this study did not consider satisfaction of sleep quality in the adolescents surveyed, one of the main factors associated with increased risk of suicide and depressive symptoms. Issue that was considered in the Korean studies of Park S et al., ${ }^{27}$ or that of
Kim SY et al., ${ }^{25}$ in which in chronic consumers there is a significant increase in committing suicide attempts, along with an unsatisfactory rest and an increased state of stress.

\section{Substance abuse}

The initiation of substance abuse occurs between the ages of 14 and 18 , often preceded by emotional problems such as depression or anxiety. The presence of both tend to generate severe depressive episodes that increase the risk of suicide. ${ }^{22}$ In longitudinal studies such as Barrense-Dias Y et al., ${ }^{28}$ Marmorstein $\mathrm{NR}^{29}$ and Choi HJ et al., ${ }^{30}$ it has been observed that adolescents who frequently consume EDs, begin to abuse alcohol, tobacco and cannabis long before the rest. This exposes them to assume high-risk behaviours with serious consequences for their health, especially for those who mix them with alcohol. Likewise, it has been observed that greater parental control can act as a protective factor to avoid substance abuse. ${ }^{29}$ AmED generated enough alarms to be banned in countries like the USA. In fact, it was in this same country that the so-called "alcoholic drinks pre-mixed with caffeine" were born in early 2000. But after 5 years of its launch, cases of ethyl overdose, sudden death and deadly accidents directly related to the consumption of the so-called "premixed drinks" led to its prohibition. ${ }^{31}$ However, far from eradicating this consumption habit, it has become a self-taught person practice far from the control of health authorities, in which adolescents decide to mix both drinks as they desire. The most common combinations are vodka with Red Bull ${ }^{\mathrm{TM}}$ and "jägermeister" liquor with any energy drink (colloquially known as "Jagerbomb"). ${ }^{32}$

When mixing alcohol with EDs, there is a greater tendency to "binge drinking", alcohol intoxication, alcohol dependence, drunk driving, not wearing a seat belt in the car, car accidents, situations of physical violence, poor school performance, promiscuity and consumption of illicit drugs, tobacco and marijuana. ${ }^{31,33,34}$ In Marczinski CA's review ${ }^{31}$ we find that this mixture increases the desire to consume more alcohol, as the combination of both drinks generates a perception of less alcoholic intoxication and fatigue as described by Lalanne L et al. ${ }^{35}$ Due to the perception of adverse effects arising from decreased alcohol consumption, does not mean that there is no increase in reaction time, decreased attention capacity, less motor coordination and high blood alcohol levels. This terminology was coined with the term "drunk awake". ${ }^{35}$

\section{Discussion}

Several authors agree that the lack of knowledge about the risks involved in the consumption of EDs favours such consumption, ${ }^{10-13}$ showing that adolescents who have more knowledge about the risks of these drinks do not consume or do so exceptionally. ${ }^{12}$ However, not enough interventions are made to address this situation. In fact, only 1 in 9 adolescents receives advice from their doctor or nurse about this type of beverage. ${ }^{36}$ Likewise, the existence of studies in which mobile applications have been shown to be useful in reducing prevalence show the usefulness of tools such as "health education" in this problem. ${ }^{37}$ As for the consumer profile, it is closely linked to the masculine gender and sport. There are studies that have demonstrated the presence of ergogenic effect and greater vigour during the exercise or sport, which could explain the success of this type of EDs in the field of sport added to the aggressive marketing campaigns. ${ }^{15-19}$ Similarly, the review by Visram S et al., ${ }^{38}$ which, on the contrary, does not emphasize the importance of the absence of a safety limit and the presence of adverse effects in all studies, which makes the recommendation for this type of use impossible. 
Following the analysis of results, it has also been observed that chronic consumers of EDs have school and affective problems and may disrupt teens' sleep patterns, that leads them to acquire violent behaviour and substance abuse. ${ }^{20-25,27}$ Likewise, the review by Richards $\mathrm{G}$ et al., ${ }^{26}$ which postulates that this type of discovery could be linked to the prejudicial effect that EDs have on adolescents' rest. Longitudinally, the ingestion of EDs predicts an abuse of alcohol, tobacco and marijuana, as well as an initiation to substance use before the age of $14 . .^{28-30}$ That is, it is a risk factor, whether it is mixed with EDs. ${ }^{40}$ Although, AmED remains being one of the greatest current risks of alcoholic dependence, alcohol intoxication and binge-drinking among adolescents. ${ }^{31-35}$ This combination of drinks favours the excessive consumption of alcohol, being its main claim the taste. ${ }^{31,32,35}$ Among the main weaknesses, the small number of works carried out in Spain in adolescent's population prevent us from knowing if the behaviours described in publications are reproduced significantly in our society. Likewise, although there are cross-sectional studies carried out by nurses, these do not translate into intervention proposals aimed at preventing the abuse of EDs and their consequences in health. Possibly the latter is due to the general lack of analytical studies that allow establishing causal relationships to give the problem the relevance and severity that the cross-sectional studies seem to suggest.

\section{Conclusion}

After the narrative review we can affirm that adolescents knowledge about the characteristics of EDs determines a lower consumption of these. On the other hand, consumption is mainly a habit of male gender, perceived as unhealthy. Chronic use of EDs causes insomnia and daytime fatigue, this favours the development of depressive symptoms and a continuous tendency to risk taking behaviours. It would be convenient to develop nursing interventions from Primary Health Care aimed at providing knowledge and favouring attitudes and skills in adolescents to prevent the abuse of EDs. From this perspective, this work could serve as a starting point, not only as a basis for future interventions, but to highlight the importance of recording the presence of this consumption habit in nursing assessment to continue exploring its impact in adolescents health.

\section{Acknowledgments}

None.

\section{Funding details}

None.

\section{Conflicts of interest}

The author declares there is no conflict of interest.

\section{References}

1. WHO. Organización Mundial de la Salud. Copenhague: Energy drinks cause concern for health of young people. 2014.

2. De Sanctis V, Soliman N, Soliman AT, et al. Caffeinated energy drink consumption among adolescents and potential health consequences associated with their use: a significant public health hazard. Acta Biomed. 2017;23;88(2):222-231.

3. Curran CP, Marczinski CA. Taurine, caffeine, and energy drinks: Reviewing the risks to the adolescent brain. Birth Defects Res. 2017;109(20):1640-1648
4. Gurley BJ, Steelman SC, Thomas SL. Multi-ingredient, caffeinecontaining dietary supplements: history, safety, and efficacy. Clin Ther. 2015;37(2):275-301.

5. Reglamento (UE) $N^{o} 1169 / 2011$ del Parlamento Europeo y del Consejo de 25 de octubre de 2011, sobre la información alimentaria facilitada al consumidor. Diario Oficial de la Unión Europea L 304/18. 2011. p. 1-46.

6. Reissig CJ, Strain EC, Griffiths RR. Caffeinated energy drinks: A growing problem. Drug Alcohol Depen. 2008;99(1):1-10.

7. Zucconi S, Volpato C, Adinolfi F, et al. Gathering consumption data on specific consumer groups of energy drinks. Supporting Publications. 2013;EN-394. p. 190

8. Enriquez A, Frankel DS. Arrhythmogenic effects of energy drinks. $J$ Cardiovasc Electrophysiol. 2017;28(6):711-717.

9. EFSA NDA Panel (EFSA Panel on Dietetic Products, Nutrition and Allergies). Scientific Opinion on the safety of caffeine. EFSA Journal. 2015;13(5):4102.

10. Francis J, Martin K, Costa B, et al. Informing Intervention Strategies to Reduce Energy Drink Consumption in Young People: Findings from Qualitative Research. J Nutr Educ Behav. 2017;49(9):724-733.

11. Scuri S, Petrelli F, Tesauro M, et al. Energy drink consumption: a survey in high school students and associated psychological effects. J Prev Med Hyg. 2018;59(1):E75-E79.

12. Mansour B, Amarah W, Nasralla E, et al. Energy drinks in children and adolescents: demographic data and immediate effects. Eur J Pediatr. 2019;178(5):649-656.

13. Costa BM, Hayley A, Miller P. Young adolescents' perceptions, patterns, and contexts of energy drink use. A focus group study. Appetite. 2014;80:183-189.

14. Costa BM, Hayley A, Miller P. Adolescent energy drink consumption: An Australian perspective. Appetite. 2016;105:638-642.

15. Emond JA, Sargent JD, Gilbert-Diamond D. Patterns of Energy Drink Advertising Over US Television Networks. J Nutr Educ Behav. 2015;47(2):120-126.

16. Nowak D, Jasionowski A. Analysis of Consumption of Energy Drinks by a Group of Adolescent Athletes. Int J Environ Res Public Health. 2016;13(8):pii: E768.

17. Gallo-Salazar C, Areces F, Abián-Vicén J, et al. Enhancing Physical Performance in Elite Junior Tennis Players with a Caffeinated Energy Drink. Int J Sport Physiol. 2015;10(3):305-310.

18. Arazi H, Najafdari A, Eghbali E. Effect of Big Bear energy drink on performance indicators, blood lactate levels and rating of perceived exertion in elite adolescent female swimmers. Prog Nutr. 2016;18(4):403410 .

19. Abian-Vicen J, Puente C, Salinero JJ, et al. A caffeinated energy drink improves jump performance in adolescent basketball players. Amino Acids. 2014;46(5):1333-1341.

20. Husarova D, Blinka L, Madarasova Geckova A, et al. Do sleeping habits mediate the association between time spent on digital devices and school problems in adolescence? Eur J Public Health. 2018;28(3):463-468.

21. Marmorstein NR. Interactions between Energy Drink Consumption and Sleep Problems: Associations with Alcohol Use among Young Adolescents. J Caffeine Res. 2017;7(3):111-116.

22. Logan RW, Hasler BP, Forbes EE, et al. Impact of Sleep and Circadian Rhythms on Addiction Vulnerability in Adolescents. Biol Psychiatry. 2018;83(12):987-996.

23. Holubcikova J, Kolarcik P, Madarasova Geckova A, et al. Regular energy drink consumption is associated with the risk of health and behavioural problems in adolescents. Eur J Pediatr. 2017;176(5):599-605. 
24. Schwartz DL, Gilstad-Hayden K, Carroll-Scott A, et al. Energy drinks and youth self-reported hyperactivity/inattention symptoms. Acad Pediatr. 2015;15(3):297-304.

25. Kim SY, Sim S, Choi HG. High stress, lack of sleep, low schoo performance, and suicide attempts are associated with high energy drink intake in adolescents. PLOS ONE. 2017;12(11):e0187759.

26. Cofini V, Cecilia MR, DI Giacomo D, et al. Energy drinks consumption in Italian adolescents: preliminary data of social, psychological and behavioral features. Minerva Pediatr. 2016.

27. Park S, Lee Y, Lee JH. Association between energy drink intake, sleep, stress, and suicidality in Korean adolescents: energy drink use in isolation or in combination with junk food consumption. Nutr J. 2016;15(1):87.

28. Barrense-Dias Y, Berchtold A, Akre C, et al. Consuming energy drinks at the age of 14 predicted legal and illegal substance use at 16. Acta Paediatr. 2016;105(11):1361-1368

29. Marmorstein NR. Investigating associations between caffeinated beverage consumption and later alcohol consumption among early adolescents. Addict Behav. 2019;90:362-368.

30. Choi HJ, Wolford-Clevenger C, Brem MJ, et al. The temporal association between energy drink and alcohol use among adolescents: A short communication. Drug Alcohol Depend. 2016;158:164-166.

31. Marczinski CA. Can energy drinks increase the desire for more alcohol? Adv Nutr. 2015;6(1):96-101.

32. Bonar EE, Cunningham RM, Polshkova S, et al. Alcohol and energy drink use among adolescents seeking emergency department care. Addict Behav. 2015;43:11-17.
33. Williams RD, Housman JM, Woolsey CL, et al. High-Risk Driving Behaviors Among 12th Grade Students: Differences Between AlcoholOnly and Alcohol Mixed With Energy Drink Users. Subst Use Misuse. 2018;53(1):137-142.

34. Holubcikova J, Kolarcik P, Madarasova Geckova A, et al. Young adolescents who combine alcohol and energy drinks have a higher risk of reporting negative behavioural outcomes. Int $J$ Public Health. 2017;62(3):379-386.

35. Lalanne L, Lutz P, Paille F. Acute impact of caffeinated alcoholic beverages on cognition: A systematic review. Prog Neuropsychopharmacol Biol Psychiatry. 2017;76:188-194.

36. Kumar G, Park S, Onufrak S. Perceptions about energy drinks are associated with energy drink intake among U.S. youth. Am J Health Promot. 2015;29(4):238-244.

37. Kapitány-Fövény M, Vagdalt E, Ruttkay Z, et al. Potential of an Interactive Drug Prevention Mobile Phone App (Once Upon a High): Questionnaire Study Among Students. JMIR Serious Games. 2018;6(4):e19.

38. Visram S, Cheetham M, Riby DM, et al. Consumption of energy drinks by children and young people: a rapid review examining evidence of physical effects and consumer attitudes. BMJ Open. 2016;6:e010380.

39. Richards G, Smith AP. A Review of Energy Drinks and Mental Health, with a Focus on Stress, Anxiety, and Depression. J Caffeine Res. 2016;6(2):49-63.

40. Breda JJ, Whiting SH, Encarnação R, et al. Energy drink consumption in Europe: a review of the risks, adverse health effects, and policy options to respond. Front Public Health. 2014;2:134. 